\title{
Are context-specific measures of parental-reported physical activity and sedentary behaviour associated with accelerometer data in 2-9-year-old European children?
}

\author{
Vera Verbestel ${ }^{1, *}$, Stefaan De Henauw ${ }^{2}$, Karin Bammann ${ }^{3,4}$, Gianvincenzo Barba ${ }^{5}$, \\ Charalambos Hadijgeorgiou6, Gabriele Eiben7, Kenn Konstabel ${ }^{8}$, Eva Kovács ${ }^{9}$, \\ Yannis Pitsiladis ${ }^{10}$, Lucia Reisch ${ }^{11}$, Alba M Santaliestra-Pasías ${ }^{12}$, Lea Maes ${ }^{2}$ and \\ Ilse De Bourdeaudhuij ${ }^{1}$, on behalf of the IDEFICS Consortium \\ 'Department of Movement and Sports Sciences, Ghent University, Watersportlaan 2, Ghent 9000, Belgium: \\ ${ }^{2}$ Department of Public Health, Ghent University, Ghent, Belgium: ${ }^{3}$ Institute for Public Health and Nursing Research, \\ University of Bremen, Bremen, Germany: ${ }^{4}$ BIPS - Institute for Epidemiology and Prevention Research GmbH, Bremen, \\ Germany: ${ }^{5}$ Institute of Food Sciences, Unit of Epidemiology and Population Genetics, National Research Council, \\ Avellino, Italy: ${ }^{6}$ Research and Education Institute for Child Health, Strovolos, Cyprus: ${ }^{7}$ Department of Public Health \\ and Community Medicine, Sahlgrenska Academy, University of Gothenburg, Gothenburg, Sweden: ${ }^{8}$ National \\ Institute for Health Development, Tallinn, Estonia: ${ }^{9}$ Department of Pediatrics, University of Pécs, Pécs, Hungary: \\ ${ }^{10}$ College of Medical, Veterinary and Life Sciences, University of Glasgow, Glasgow, UK: ${ }^{11}$ Department of \\ Intercultural Communication and Management, Copenhagen Business School, Frederiksberg, Denmark: ${ }^{12}$ GENUD \\ (Growth, Exercise, Nutrition and Development) Research Group, University School of Health Sciences, University of \\ Zaragoza, Zaragoza, Spain
}

Submitted 15 March 2013: Final revision received 26 September 2013: Accepted 2 April 2014: First published online 2 June 2014

\begin{abstract}
Objective: The aim of the present study was to investigate if context-specific measures of parental-reported physical activity and sedentary behaviour are associated with objectively measured physical activity and sedentary time in children. Design: Cross-sectional study.

Setting: Seven European countries taking part in the IDEFICS (Identification and Prevention of Dietary- and Lifestyle-induced Health Effects in Children and Infants) study.

Subjects: Data were analysed from 2-9-year-old children ( $n$ 5982) who provided both parental-reported and accelerometer-derived physical activity/sedentary behaviour measures. Parents reported their children's daily screen-time, weekly sports participation and daily outdoor playtime by means of the Outdoor Playtime Checklist (OPC) and Outdoor Playtime Recall Questions (OPRQ).

Results: Sports participation, OPC- and OPRQ-derived outdoor play were positively associated with accelerometer-derived physical activity. Television viewing and computer use were positively associated with accelerometer-derived sedentary time. All parental-reported measures that were significantly associated with accelerometer outcomes explained only a minor part of the variance in accelerometer-derived physical activity or sedentary time.

Conclusions: Parental-reported measures of physical activity and sedentary behaviour are not useful as a proxy for 2-9-year-old children's physical activity and sedentary time. Findings do not preclude the use of context-specific measures but imply that conclusions should be limited to the context-specific behaviours that are actually measured. Depending on the aim of the study, future research should carefully consider the choice of measurements, including the use of subjective or objective measures of the behaviour of interest or a combination of both.
\end{abstract}

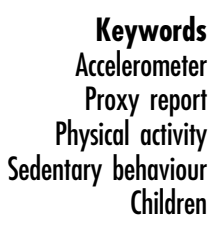

In light of the current prevalence of childhood obesity observed worldwide, there is a growing research interest in children's physical activity (PA) and sedentary behaviour (SB). Accurate measurements of these behaviours

are important not only for investigating the associations with health outcomes but also to evaluate the effectiveness of interventions aiming to promote PA and reduce $\mathrm{SB}$. 
Accelerometry is a commonly used method to objectively assess children's daily PA and sedentary time with proven validity and reliability ${ }^{(1)}$. Despite the known advantages of accelerometers, they have some shortcomings that can be addressed by using survey instruments such as a questionnaire. First, accelerometers are not able to provide contextual information about children's PA and SB. They do not provide information on the type of $\mathrm{PA}$ (e.g. structured $v$. unstructured) or SB (e.g. television (TV) viewing, computer use, painting) and the setting in which it was performed (e.g. at school or at home). Furthermore, the use of accelerometry is not always feasible in large-scale population-based studies and depending on the outcome of interest (e.g. rank ordering of children), might unnecessarily impose more participant and researcher burden and imply unnecessarily higher costs ${ }^{(2)}$.

Questionnaires are survey instruments extensively used to assess PA and SB across all ages, also in children younger than 12 years old where the assessment must rely on a proxy reporter such as a parent/legal guardian or a teacher. Despite the advantage of questionnaires to provide contextual information about PA and SB, they are hardly ever used for these purposes in children. Instead, context-specific measures of parental-reported PA or SB are mostly used as a substitute for the time children spend being physically active or sedentary. For example, parental-reported outdoor play is a context-specific survey measure used as a proxy for children's $\mathrm{PA}^{(3,4)}$ while screen-time behaviour is used as a surrogate for an overall sedentary lifestyle ${ }^{(5,6)}$. However, there is a current lack of evidence demonstrating that context-specific survey measures of PA and SB are representative for children's overall PA and sedentary time.

In the IDEFICS (Identification and Prevention of Dietary and Lifestyle induced Health Effects in Children and Infants) study, a multi-centre European project aiming at the prevention of childhood obesity in 2-9-year-olds, accelerometer-derived and context-specific parentalreported PA (i.e. outdoor play and sports participation) and SB (i.e. TV viewing and computer use) were assessed in parallel. This provided a unique opportunity to address the above explained gap in the literature and allowed us to investigate: (i) if children's parental-reported outdoor play and sports participation are associated with children's daily accelerometer-derived PA; and (ii) if parentalreported TV viewing and computer use are associated with children's daily accelerometer-derived sedentary time in 2-9-year-old children.

\section{Methods}

\section{Participants}

The children included in the present study are all participants from the baseline survey of the IDEFICS project (www.idefics.eu), a European cohort study to investigate the aetiology of diet- and lifestyle-related diseases and disorders in children and to develop and evaluate a primary prevention programme focusing on childhood obesity. A population-based sample of 16225 children aged 2-9 years was recruited in eight different European countries (Belgium, Cyprus, Estonia, Germany, Hungary, Italy, Spain and Sweden).

In total, 31543 children aged $2-9$ years were contacted and 16864 of them gave their consent and participated in the baseline survey ( $53 \%$ of those invited). The completion of the parental questionnaire and the measurement of height and weight were required to be valid for inclusion in the IDEFICS database and were met by 16225 children (96\% of those who consented). A more detailed description of the IDEFICS study population is given by Ahrens et al. ${ }^{(7)}$.

Because of budgetary and feasibility reasons, a random sub-sample of children who consented to participate in the IDEFICS study was selected to wear an accelerometer to objectively measure their PA and sedentary time ( $n$ 9184; $54 \%$ of those who consented). To be eligible for inclusion in the analyses of the present paper, children had to provide valid accelerometer data ( $n 6202 ; 68 \%$ of the sub-sample) and at least one measure of parentalreported PA or SB. This resulted in a final sample of 5982 children ( $65 \%$ of the initial sub-sample). The mean age of this sample was 6.08 (SD 1.78) years and boys $(50.5 \%)$ and girls were equally represented.

Written informed consent was obtained from the child's parent or legal guardian in the participating schools. All participating countries were granted ethical approval for the study by their respective ethical committees.

\section{Procedure}

All data were collected simultaneously in all centres between September 2007 and June 2008. Standard operating procedures were available in a central survey manual to standardize data collection across countries ${ }^{(8)}$. A parental questionnaire, previously tested for its comprehensibility, length, structure and acceptance by the parents ${ }^{(8)}$, was used to assess sociodemographic data and parental-reported measures of children's PA and SB. Parents were requested to complete the questionnaire at home or during the examinations.

Children's PA and sedentary time were objectively measured by means of accelerometry. Children of parents who consented for their child to wear the accelerometer were asked to wear the accelerometer for at least three days, including one weekend day. Consistent with previous studies ${ }^{(9)}$, the accelerometer was worn at the right hip with an adjustable elastic band. Parents were asked to have their child wear the accelerometer at all times during the day and to remove it only when performing waterbased activities or activities for which the accelerometer 
would expose them to risk for injury. Parents were also asked to remove the monitor at night and to reattach it as soon as the child got up in the morning. Children wore the accelerometer regardless of the day the parents completed the questionnaire.

\section{Measurements}

Parental questionnaire: sociodemographic information Parental socio-economic status (SES) and children's sex and age were reported by one of the parents (or legal guardians). SES was estimated on the basis of the highest education of both parents, which was classified according to the International Standard Classification of Education (ISCED; http://www.unesco.org/education/information/ nfsunesco/doc/isced_1997.htm). For descriptive purposes, the highest parental education of both parents was coded as low (ISCED Levels 1 and 2; $\leq 9$ years of education), medium (ISCED Levels 3 and 4) and high (ISCED Levels 5 and $6 ; \geq 2$ years of education after high school) SES.

\section{Parental questionnaire: physical activity}

The parental questionnaire included three context-specific measures of PA: two separate measures of outdoor play and one measure of sports participation. In prior observational studies, time spent outdoors was correlated with children's $\mathrm{PA}^{(10)}$. In the present study, assessment of time playing outdoors was based on the Outdoor Playtime Checklist (OPC) and the Outdoor Playtime Recall Questions (OPRQ) - two instruments previously developed for this purpose and tested by Burdette et al. ${ }^{(11)}$.

The OPC (two closed-ended questions) assesses daily time usually spent in outdoor play in two different locations: (i) outdoor play in the yard or street around the house; and (ii) outdoor play in the park, playground or outdoor recreation. For both questions, five response categories were given separately for three different periods of the day: (i) wake-up time until noon; (ii) noon until $6 \mathrm{pm}$; and (iii) $6 \mathrm{pm}$ until bedtime. Response categories were converted using the same scoring system as Burdette et al. ${ }^{(11)}: 0 \mathrm{~min}=0,1-15 \mathrm{~min}=1,16-30 \mathrm{~min}=2$, $31-60 \mathrm{~min}=3$ and $>60 \mathrm{~min}=4$. Summing the responses across both questions resulted in a score ranging from 0 to 24. The difference between the questions used in the present study and in the study of Burdette et $a l .^{(11)}$ is that the present study asked parents once about the time their child usually spends outdoors, while the original procedure for the OPC from Burdette et $a l .{ }^{(11)}$ is to have it completed by the parents on two weekdays and one weekend day, coinciding with the days on which the accelerometer is worn. Burdette et al. reported a positive association between OPC-derived outdoor play and accelerometer-derived PA $(r=0.33 ; P<0 \cdot 001)^{(11)}$.

The OPRQ (two open-ended questions) assessed the time children played outdoors during the past month. Parents were asked to recall how many hours and minutes (as a continuous variable) their child plays outdoors during a typical weekday and weekend day separately. The final outdoor play measure in $\mathrm{min} / \mathrm{d}$ was calculated as follows: [(outdoor play weekday $\times 5$ ) + (outdoor play weekend day $\times 2)] / 7$. OPRQ-derived outdoor play was found to be positively associated with accelerometerderived PA $(r=0.20 ; P=0.003)$ in the study of Burdette et $a l .{ }^{(11)}$. The OPRQ has also been used in Upstate KIDS, an Infant Development Screening Program in New York State to track growth and development from children aged 24 months onwards ${ }^{(12)}$.

The third context-specific measure of PA assessed how many hours and minutes a child spends in a sports club during an average week (as a continuous variable). Responses were converted into minutes and divided by seven to obtain a measure of children's daily sports participation $(\mathrm{min} / \mathrm{d})$.

All PA questions were included in a pilot study testing reproducibility of the parental questionnaire ( $n$ 421). Test-retest reliability was shown to be good for sports participation (intra-class correlation $(\mathrm{ICC})=0 \cdot 78$ ) but was found to be poor for the OPC (ICC $=0.35,0.45)$ and the OPRQ (ICC $=0.46,0 \cdot 47)$.

\section{Parental questionnaire: sedentary behaviour}

The parental questionnaire assessed screen-time behaviour by using (i) a closed-ended question about usual time watching TV, video and/or digital video disk per day (from now on called 'TV viewing') and (ii) a close-ended question about usual time using the computer and/or game console per day (from now on called 'computer use'), with separate answers given for weekdays and weekend days. For both questions, six response categories were provided and converted based on the scoring system as used for the OPC (see above): not at all $=0,<30$ $\min =1, \quad<1 \mathrm{~h}=2, \quad 1-<2 \mathrm{~h}=3,2-3 \mathrm{~h}=4$ and $>3 \mathrm{~h}=5$. Responses were weighted and summed across weekdays and weekend days as follows: [(weekday score $\times 5)+$ (weekend day score $\times 2$ )]. This resulted in a score ranging from 0 to 35 for TV viewing and computer use separately. The questions were taken and adapted from the Generation M-study, a nationally representative survey to assess children's media use in the USA ${ }^{(13)}$. Test-retest reliability in the IDEFICS study ( $n$ 421) was shown to be good for TV viewing during weekdays (ICC $=0.71$ ) and weekend days (ICC $=0.66)$ and computer use during weekend days (ICC $=0.74$ ), but not for computer use during weekdays (ICC $=0 \cdot 49)$.

All PA and SB questions and their respective responses are described in Table 1.

\section{Accelerometry: physical activity and sedentary time}

Daily PA and sedentary time were objectively assessed using the ActiGraph ${ }^{\mathrm{TM}}$ and the ActiTrainer ${ }^{\mathrm{TM}}$ (Pensacola, FL, USA) uniaxial accelerometer. The accelerometers were initialized to save data over $15 \mathrm{~s}$ epochs because children 
Table 1 Descriptive statistics of sociodemographic data, parental-reported and accelerometer-derived physical activity and sedentary behaviour in 2-9-year-old children from seven European countries taking part in the IDEFICS study, September 2007-June 2008

\begin{tabular}{|c|c|c|c|c|c|c|}
\hline \multirow[b]{2}{*}{ Variable } & \multirow[b]{2}{*}{ Description of the item } & \multirow[b]{2}{*}{ Response } & \multicolumn{4}{|c|}{ Descriptive statistics } \\
\hline & & & $n$ & $\%$ & Mean & SD \\
\hline $\begin{array}{l}\text { Sociodemographic data } \\
\text { Number } \\
\text { Age (years) } \\
2-5 \text {-year-olds (\%) } \\
\text { Boys (\%) } \\
\text { Low SES (\%) } \\
\text { Medium SES (\%) } \\
\text { Overweight and obese† (\%) }\end{array}$ & & & 5982 & $\begin{array}{r}44 \cdot 2 \\
50 \cdot 6 \\
9 \cdot 4 \\
49 \cdot 9 \\
16 \cdot 3\end{array}$ & 6.08 & 1.78 \\
\hline $\begin{array}{l}\text { Context-specific parental-reported meas } \\
\text { Sports participation } \\
\text { ( } 2 \text { items; final measure in } \mathrm{min} / \mathrm{d})\end{array}$ & $\begin{array}{l}\text { 1. Is your child member in a sports club? } \\
\text { 2. How much time does he/she spend doing sport in a sports club per week? }\end{array}$ & $\begin{array}{l}\text { Yes/No } \\
\text { Hours and minutes } \\
\text { (continuous) }\end{array}$ & & & $7 \cdot 26$ & 9.98 \\
\hline $\begin{array}{l}\text { OPC-derived outdoor play } \\
\text { (6 items; final measure from } 0 \text { to } 24 \text { ) }\end{array}$ & $\begin{array}{l}\text { 1. How much time does your child usually spend per day playing in the yard or } \\
\text { street around your house (or the house of a friend, neighbour or relative)? } \\
\text { Please indicate for every time frame. Include times while the child is at day } \\
\text { care, kindergarten, pre-school or school. } \\
\text { a. Wake-up time until noon } \\
\text { b. Noon until } 6 \text { pm } \\
\text { c. } 6 \text { pm until bedtime } \\
\text { 2. How much time does your child usually spend per day at a park, playground } \\
\text { or outdoor recreation area (e.g. swimming pool, zoo or amusement park)? } \\
\text { Please indicate for every time frame. Include times while the child is at day } \\
\text { care, kindergarten, pre-school or school. } \\
\text { a. Wake-up time until noon } \\
\text { b. Noon until } 6 \mathrm{pm} \\
\text { c. } 6 \mathrm{pm} \text { until bedtime }\end{array}$ & $\begin{array}{l}\text { 5-point scalell } \\
\text { (for each time frame) }\end{array}$ & & & $12 \cdot 14$ & 4.82 \\
\hline $\begin{array}{l}\text { OPRQ-derived outdoor play } \neq \\
\text { ( } 2 \text { items; final measure in } \mathrm{min} / \mathrm{d} \text { ) }\end{array}$ & $\begin{array}{l}\text { 1. Think for a moment about a typical weekday for your child in the last month. } \\
\text { How much time would you say your child spends playing outdoors on a } \\
\text { typical weekday? } \\
\text { 2. Now think about a typical weekend day for your child in the last month. How } \\
\text { much time would you say your child spends playing outdoors on a typical } \\
\text { weekend day? }\end{array}$ & $\begin{array}{l}\text { Hours and minutes } \\
\text { (continuous) }\end{array}$ & & & 133.99 & 59.60 \\
\hline $\begin{array}{l}\text { TV viewing§ } \\
\text { ( } 2 \text { items; final measure from } 0 \text { to } 35 \text { ) }\end{array}$ & $\begin{array}{l}\text { How long does your child usually watch TV/video/DVD per day? } \\
\text { a. During weekdays } \\
\text { b. During Saturdays/Sundays }\end{array}$ & $\begin{array}{l}\text { 6-response category } \pi \\
\text { (for each time frame) }\end{array}$ & & & 17.98 & $6 \cdot 48$ \\
\hline $\begin{array}{l}\text { Computer use§ } \\
\text { ( } 2 \text { items; final measure from } 0 \text { to } 35 \text { ) }\end{array}$ & $\begin{array}{l}\text { How long does your child usually sit at a computer/game console per day? } \\
\text { a. During weekdays } \\
\text { b. During Saturdays/Sundays }\end{array}$ & $\begin{array}{l}\text { 6-response category } \\
\text { (for each time frame) }\end{array}$ & & & 5.53 & 6.45 \\
\hline $\begin{array}{l}\text { Accelerometer-derived measures } \\
\text { cpm/d } \\
\text { LPA }(\% \text { of time/d) } \\
\text { MVPA (\% of time/d) } \\
\text { ST }(\% \text { of time/d) }\end{array}$ & & & & & $\begin{array}{r}605 \cdot 15 \\
40 \cdot 17 \\
7.82 \\
52 \cdot 01\end{array}$ & $\begin{array}{r}165.49 \\
7.08 \\
3.07 \\
8.53\end{array}$ \\
\hline
\end{tabular}

IDEFICS, Identification and Prevention of Dietary and Lifestyle induced Health Effects in Children and Infants; SES, socio-economic status (as defined by the highest parental education of both parents classified according to the International Standard Classification of Education); OPC, Outdoor Playtime Checklist; OPRQ, Outdoor Playtime Recall Questions; TV, television; cpm, counts per minute; LPA, light physical activity; MVPA, moderate-to-vigorous physical activity; ST, sedentary time; DVD, digital video disk.

$\ddagger$ Average per day, weighted for weekdays and weekend days.

$\S$ Weighted sum score for weekdays and weekend days.

$110 \mathrm{~min}, 1-15 \mathrm{~min}, 16-30 \mathrm{~min}, 31-60 \mathrm{~min},>60 \mathrm{~min}$.

INot at all, $<30 \mathrm{~min} / \mathrm{d},<1 \mathrm{~h} / \mathrm{d}$, approximately $1-2 \mathrm{~h} / \mathrm{d}$, approximately $2-3 \mathrm{~h} / \mathrm{d},>3 \mathrm{~h} / \mathrm{d}$. 
tend to perform spontaneous and intermittently short bouts of $\mathrm{PA}^{(9)}$.

The accelerometer output was edited using a computer program in $\mathrm{R}$ (version R 2.9.0, R Foundation for Statistical Computing, Vienna, Austria; http://www.R-project.org) specifically developed for the IDEFICS project by the National Institute for Health Development (Estonia) and the University of Glasgow (UK). The program contains an algorithm to remove periods corresponding to sleep and any period containing $20 \mathrm{~min}$ or more of consecutive zero counts. To be included as a valid measurement day, the accelerometer was required to contain at least six hours of registered activities. A monitoring period of six hours or more has been shown to provide an acceptable reliability in young children ${ }^{(14)}$ and is in line with other studies ${ }^{(15,16)}$. Participants were included in the analyses only if they had three valid days of monitoring.

Counts per minute per day $(\mathrm{cpm} / \mathrm{d}$; average over all valid days) were calculated and for descriptive purposes dichotomized into 'low active' and 'high active' based on the median $(587.96 \mathrm{cpm} / \mathrm{d})$. Activity counts were classified as sedentary time ( $\leq 25 / 15 \mathrm{~s}$ ), light PA (LPA; $\geq 26-573 / 15 \mathrm{~s}$ ) and moderate-to-vigorous PA (MVPA; $\geq 574 / 15$ s) according to cut-off points of Evenson et al. ${ }^{(17)}$. It is currently recommended to use the cut-off of 25 counts per $15 \mathrm{~s}$ to define sedentary time in toddlers, pre-schoolers and children $^{(18,19)}$. This cut-off is also used in large studies across Europe ${ }^{(20)}$ and the USA ${ }^{(21)}$. To account for potential differences in wearing time, percentage of time (average over all valid days) spent in sedentary time, LPA and MVPA were used in the analyses.

Although the minimal criterion of six hours of wear time per day does not cover all waking hours, it provides acceptable reliable estimates of PA and sedentary time in young children if it is measured over at least three days ${ }^{(14,22)}$. The criterion is also in line with other studies $^{(15,16)}$ and valid wearing time of the included sample was longer in practice (mean 11.68 (SD 1.64) h/d).

\section{Statistical analyses}

The statistical software package IBM SPSS Statistics for Windows version 19 was used to obtain descriptive statistics and to study the characteristics of sub-sample participation. Descriptive statistics were computed for sociodemographic data and all behavioural measures and are reported as percentages or as means and standard deviations. In line with other research in the IDEFICS study ${ }^{(23,24)}$, logistic regression analyses were used to investigate differences in sociodemographic data between the children who were included in the analyses and those who were not.

Multivariate regression analyses were conducted using MLwiN 2·16. Prior to analyses, all measures were checked for normal distribution. Parental-reported computer use was positively skewed and therefore logarithmically transformed $\left(\log _{10}(1+x)\right.$ to deal with zero values). For the explanatory variables that were continuously reported by the parents, values above the 95th percentile were first removed to improve normality. Time participating in sports $(\mathrm{min} / \mathrm{d})$ remained positively skewed and was then logarithmically transformed $\left(\log _{10}(1+x)\right)$. For descriptive purposes, nontransformed data were reported.

Multilevel modelling (three level: children-schoolcountry with a random intercept at school level and country level) was applied to take clustering of children within schools and within countries into account. Multilevel regression models were used to examine the associations between parental-reported measures of PA and SB (explanatory variables) and accelerometer-derived PA and sedentary time (dependent variables). Preliminary analyses showed no moderating effect of gender and age (2-5-year-olds $v$. 6-9-year-olds) on the associations between parental-reported and accelerometer-derived measures. Multilevel regression analyses were therefore conducted in the total sample.

Gender, age and parental education (maximum of both parents as indicator for SES) were included as a first block of variables in the regression analyses to adjust subsequent analyses for these variables (i.e. the null model). Sports participation, OPC-derived outdoor play, OPRQ-derived outdoor play, TV viewing and computer use were then separately added to the model to investigate their independent association with the accelerometer-derived measures (i.e. five full models, one separate model for each parental-reported measure). To estimate between-pupil variance in accelerometer-derived measures explained by the parental-reported measures, the proportion of unexplained variance in the full models was compared with the null model. Stratification of all the analyses by country (seven groups) and age (six groups) revealed similar results to the total sample and are therefore not reported in the present paper. All two-sided statistical hypotheses were tested with a significance level of $\alpha=0 \cdot 05$. 
parental-reported PA or SB, resulting in a final sample of 5982 children (65\% of the initial sub-sample).

Comparison of sociodemographic data between children who satisfied the criteria to be included in the analyses ( $n$ 5982) and those who did not ( $n$ 10 243) revealed that children with parents with medium SES ( $v$. low SES: $\mathrm{OR}=1.38 ; 95 \%$ CI $1.21,1.57 ; v$. high SES: OR $=1 \cdot 21 ; 95 \%$ CI $1.12,1.31)$ and normal-weight children $(v$. overweight and obese children: $\mathrm{OR}=1 \cdot 16 ; 95 \% \mathrm{CI} 1 \cdot 04,1 \cdot 28)$ were more likely to provide both accelerometer data and at least one parental-reported measure of PA or SB. No differences were found between boys and girls $(\mathrm{OR}=1 \cdot 03$; $95 \% \mathrm{CI}$ $0.95,1.11)$ or between $2-5$-year-olds and 6-9-year-olds (OR $=1.08 ; 95 \%$ CI 1.00, 1.16).

Sample characteristics of the final sample can be found in Table 1.

\section{Physical activity}

Associations between parental-reported and accelerometerderived PA can be found in Table 2 . Higher daily sports participation was associated with more $\mathrm{cpm} / \mathrm{d}(\beta=14.95$, $\mathrm{SE}=3.71)$ and more accelerometer-derived MVPA $/ \mathrm{d}$ $(\beta=0 \cdot 38$, sE $=0 \cdot 07)$. Daily sports participation explained respectively $0.11 \%$ and $0.65 \%$ of between-pupil variance in $\mathrm{cpm} / \mathrm{d}$ and accelerometer-derived MVPA/d. Daily sports participation was not associated with accelerometer-derived $\mathrm{LPA} / \mathrm{d}(\beta=-0 \cdot 26, \mathrm{sE}=0 \cdot 14)$.

More OPRQ-derived outdoor play was associated with more accelerometer-derived PA (cpm/d: $\beta=0 \cdot 29, \mathrm{sE}=0 \cdot 04$; $\mathrm{LPA} / \mathrm{d}: \beta=0 \cdot 006, \mathrm{sE}=0 \cdot 001 ; \mathrm{MVPA} / \mathrm{d}: \beta=0 \cdot 005, \mathrm{sE}=0 \cdot 001)$. OPRQ-derived outdoor play explained respectively $4.07 \%$, $1.98 \%$ and $3.82 \%$ of between-pupil variance in $\mathrm{cpm} / \mathrm{d}$, accelerometer-derived LPA/d and accelerometer-derived MVPA/d.

More OPC-derived outdoor play was also associated with more accelerometer-derived PA $(\mathrm{cpm} / \mathrm{d}: \beta=2.93$, $\mathrm{SE}=0.48 ; \quad \mathrm{LPA} / \mathrm{d}: \quad \beta=0.08, \quad \mathrm{SE}=0.02 ; \mathrm{MVPA} / \mathrm{d}: \quad \beta=0.05$, $\mathrm{SE}=0 \cdot 01)$. OPC-derived outdoor play explained respectively $3 \cdot 16 \%, 0 \cdot 80 \%$ and $2 \cdot 86 \%$ of the between-pupil variance in $\mathrm{cpm} / \mathrm{d}$, accelerometer-derived $\mathrm{LPA} / \mathrm{d}$ and accelerometer-derived MVPA/d.

\section{Sedentary behaviour}

Associations between parental-reported SB and accelerometer-derived sedentary time can be found

Table 2 Multilevel associations between parental-reported and accelerometer-derived physical activity in 2-9-year-old children from seven European countries taking part in the IDEFICS study, September 2007-June 2008

\begin{tabular}{|c|c|c|c|c|c|c|c|c|}
\hline \multirow[b]{2}{*}{ Parameter } & \multicolumn{2}{|c|}{$\begin{array}{l}\text { Null model } \dagger \\
\text { ( } n \text { 5943) }\end{array}$} & \multicolumn{2}{|c|}{$\begin{array}{l}\text { Full model SPORT } \\
\qquad(n 5320)\end{array}$} & \multicolumn{2}{|c|}{$\begin{array}{l}\text { Full model OPRQ§ } \\
\qquad(n \text { 5147) }\end{array}$} & \multicolumn{2}{|c|}{$\begin{array}{l}\text { Full model OPC\| } \\
\qquad(n 4718)\end{array}$} \\
\hline & $\sigma^{2}$ & SE & $\sigma^{2}$ & $\mathrm{SE}$ & $\sigma^{2}$ & SE & $\sigma^{2}$ & SE \\
\hline \multicolumn{9}{|l|}{$\mathrm{cpm} / \mathrm{d}$} \\
\hline \multicolumn{9}{|l|}{ Fixed part } \\
\hline$\beta$ П & & & $14.95^{\star \star}$ & & $0.29^{* *}$ & & $2 \cdot 93^{* *}$ & \\
\hline SEף & & & 3.71 & & 0.04 & & 0.48 & \\
\hline \multicolumn{9}{|l|}{ Random part } \\
\hline Country level & $3269 \cdot 25$ & $1794 \cdot 11$ & $3006 \cdot 38$ & $1661 \cdot 32$ & 2767.65 & $1525 \cdot 03$ & $3340 \cdot 17$ & 1845.99 \\
\hline School level & $2100 \cdot 75$ & 296.09 & 2295.13 & 326.96 & 1665.07 & 269.14 & 2293.18 & 340.50 \\
\hline Child level & 21665.55 & $410 \cdot 15$ & $21642 \cdot 40$ & 433.97 & $20785 \cdot 18$ & $423 \cdot 58$ & 21008.96 & 488.63 \\
\hline \multicolumn{9}{|l|}{ LPA (\% of time/d) } \\
\hline \multicolumn{9}{|l|}{ Fixed part } \\
\hline$\beta$ П & & & -0.26 & & $0.006^{\star \star}$ & & $0.08^{\star *}$ & \\
\hline SEף & & & 0.14 & & 0.001 & & 0.02 & \\
\hline \multicolumn{9}{|l|}{ Random part } \\
\hline Country level & $5 \cdot 26$ & 2.89 & 4.82 & $2 \cdot 67$ & 5.08 & $2 \cdot 80$ & 4.82 & $2 \cdot 67$ \\
\hline School level & 4.42 & 0.55 & $4 \cdot 15$ & 0.55 & $4 \cdot 21$ & 0.56 & 3.55 & 0.52 \\
\hline Child level & $31 \cdot 76$ & 0.60 & 31.87 & 0.64 & $31 \cdot 13$ & 0.64 & 31.51 & 0.67 \\
\hline \multicolumn{9}{|l|}{ MVPA (\% of time/d) } \\
\hline \multicolumn{9}{|l|}{ Fixed part } \\
\hline$\beta \rrbracket$ & & & $0.38^{* *}$ & & $0.005^{\star *}$ & & $0.05^{\star \star}$ & \\
\hline SEI & & & 0.07 & & 0.001 & & 0.01 & \\
\hline \multicolumn{9}{|l|}{ Random part } \\
\hline Country level & 0.77 & 0.42 & 0.73 & 0.40 & 0.66 & 0.37 & 0.82 & 0.46 \\
\hline School level & 0.47 & 0.08 & 0.51 & 0.09 & 0.38 & 0.08 & 0.54 & 0.09 \\
\hline Child level & 7.64 & 0.14 & 7.59 & 0.15 & 7.35 & 0.15 & 7.43 & 0.16 \\
\hline
\end{tabular}

IDEFICS, Identification and Prevention of Dietary and Lifestyle induced Health Effects in Children and Infants; SPORT, sports participation; OPRQ, Outdoor Playtime Recall Questions; OPC, Outdoor Playtime Checklist; $\sigma^{2}$, variance; cpm, counts per minute; LPA, light physical activity; MVPA, moderate-to-vigorous physical activity; SES, socio-economic status.

${ }^{\star *} P<0.001$.

†Only including the covariates (sex, age, SES).

$\ddagger$ Null model + sports participation as an explanatory variable.

$\S N u l l$ model + OPRQ-derived outdoor play as an explanatory variable.

IINull model + OPC-derived outdoor play as an explanatory variable.

ףControlled for sex of the child, age and SES (as defined by the highest parental education of both parents). 
Table 3 Multilevel associations between parental-reported measures of sedentary behaviour and accelerometer-derived sedentary time in 2-9-year-old children from seven European countries taking part in the IDEFICS study, September 2007-June 2008

\begin{tabular}{|c|c|c|c|c|c|c|}
\hline \multirow[b]{2}{*}{ Parameter } & \multicolumn{2}{|c|}{$\begin{array}{c}\text { Null model } \dagger \\
(n \text { 5943) }\end{array}$} & \multicolumn{2}{|c|}{$\begin{array}{l}\text { Full model TV } \ddagger \\
\qquad(n 5877)\end{array}$} & \multicolumn{2}{|c|}{$\begin{array}{l}\text { Full model COMPUTERß } \\
(\text { ( } 5 \text { 5829) }\end{array}$} \\
\hline & $\sigma^{2}$ & SE & $\sigma^{2}$ & SE & $\sigma^{2}$ & SE \\
\hline \multicolumn{7}{|c|}{ Sedentary time $(\%$ of time/d) } \\
\hline SEII & & & $\begin{array}{l}0.05^{\star} \\
0.02\end{array}$ & & $\begin{array}{l}1.28^{\star *} \\
0.22\end{array}$ & \\
\hline \multicolumn{7}{|l|}{ Random part } \\
\hline $\begin{array}{l}\text { Country level } \\
\text { School level } \\
\text { Child level }\end{array}$ & $\begin{array}{r}9.59 \\
6.60 \\
49.71\end{array}$ & $\begin{array}{l}5 \cdot 25 \\
0.83 \\
0.94\end{array}$ & $\begin{array}{r}9.41 \\
6.55 \\
49.62\end{array}$ & $\begin{array}{l}5 \cdot 15 \\
0.83 \\
0.95\end{array}$ & $\begin{array}{r}10 \cdot 39 \\
6.59 \\
49 \cdot 23\end{array}$ & $\begin{array}{l}5.68 \\
0.84 \\
0.94\end{array}$ \\
\hline
\end{tabular}

IDEFICS, Identification and Prevention of Dietary and Lifestyle induced Health Effects in Children and Infants; TV, television viewing; COMPUTER, computer use; $\sigma^{2}$, variance; SES, socio-economic status.

${ }^{\star} P=0.001 ;{ }^{\star \star} P<0.001$.

tOnly including the covariates (sex, age, SES).

‡Null model + TV viewing as an explanatory variable.

$\S N u l l$ model + computer use as an explanatory variable.

IIControlled for sex of the child, age and SES (as defined by the highest parental education of both parents).

in Table 3. More TV viewing and more computer use were both associated with more accelerometer-derived sedentary time (TV viewing: $\beta=0 \cdot 05, \mathrm{sE}=0 \cdot 02$; computer use: $\beta=0 \cdot 28, \mathrm{SE}=0 \cdot 22$ ). TV viewing explained $0 \cdot 18 \%$ and computer use explained $0.97 \%$ of the between-pupil variance in accelerometer-derived sedentary time.

\section{Discussion}

The first aim of the present study was to investigate if context-specific measures of parental-reported outdoor play and sports participation are associated with objective measures of children's PA. Significant positive associations were found between parental-reported and accelerometerderived PA measures. However, very small regression coefficients were observed, indicating these associations to be weak. Also, the parental-reported measures explained only a minor part of the variance in accelerometerderived PA.

Burdette et al. ${ }^{(11)}$ previously reported a positive and acceptable association between accelerometer-derived PA and OPC-derived outdoor play $(r=0.33)$ and between accelerometer-derived PA and OPRQ-derived outdoor play $(r=0 \cdot 20)$ in 250 US pre-school children. Based on these results, the authors concluded that parental-reported outdoor play provides an acceptable surrogate of preschoolers' $\mathrm{PA}^{(11)}$. Somewhat unexpectedly, the present study was not able to confirm these conclusions in a European sample of 2-9-year-old children and suggests that parental-reported measures of outdoor play are not useful as a proxy for children's PA.

Although both outdoor play measures were significantly associated with objectively measured PA in the study of Burdette et al. ${ }^{(11)}$, they found OPC-derived outdoor play to be more promising than OPRQ-derived outdoor play.
Reasons for this were allocated to the very structured format of the OPC in which parents are prompted for time of the day, place and duration of the activity. Results of the present study do not confirm these findings by showing that the OPC and OPRQ provide comparable weak magnitudes and low proportions of explained variance in the association with accelerometer-derived PA. The success of the OPC in the study of Burdette et $a l .{ }^{(11)}$ was probably due to the fact that parents were asked to recall their children's outdoor play for specific and defined days in the past (i.e. the days on which the accelerometer was worn), while the procedure for the OPC used in the present study asked parents to recall children's usual activity.

Results from the present study do not justify the use of outdoor play measures and sports participation as a proxy of children's PA behaviour. This means that an objective measurement of PA such as accelerometry remains recommended when conducting observational or experimental studies in which it is important to assess PA at the individual level. However, results of the present study may not preclude the use of parental-reported PA measures. Survey measures of children's PA provide context-related information that may have a valuable contribution to objectively measured PA data in epidemiological and intervention-based PA research. However, to our knowledge, the field is still facing some challenges in terms of validity and reliability of context-related PA measures in children and we therefore believe that further development of these measures is urgently required.

A second aim of the present study was to investigate if TV viewing and computer use are associated with children's objectively measured sedentary time. Very weak associations were found between these parental-reported screen-time behaviours and daily time spent sedentary. These findings indicate that TV viewing and computer use are on average not good representations of an overall 
sedentary lifestyle in 2-9-year-olds. Focusing only on screen-time behaviours for the purpose of making conclusions about children's overall sedentary time might therefore be incorrect. To our knowledge, there are currently no studies available that have addressed this research question in 2-9-year-olds. However, our results are in line with studies in schoolchildren ${ }^{(25)}$, adolescents $^{(26,27)}$ and adults ${ }^{(28)}$, where self-reported TV viewing time or total screen-time behaviour was weakly associated with objectively measured sedentary time. These consistent findings across different age groups indicate that survey measures of sedentary time are in need of further development in varying age groups. More specifically, valid and reliable questionnaires that assess a wide range of domain-specific sitting activities, rather than solely assessing screen-time behaviours, have to be developed to provide a contextual measure of SB. In the meantime, parental-reported measures of TV viewing and computer use should not be precluded from further research but should be used only to make conclusions about children's screen-time behaviour. This also implies that, depending on the aim of the study, researchers should cautiously consider whether they need a contextrelated (e.g. by means of questionnaires, inclinometers) or an objective measure of SB or a combination of both.

An important strength of the IDEFICS study is its large sample size across eight different European countries and its harmonized and standardized methodology to concurrently assess both objective and subjective measures of PA and SB. Furthermore, the present study is the first one to address this research gap in such a large sample of children. The limitations to consider are the use of cut-off points to categorize accelerometer data into minutes spent in different types of activities. Despite the currently ongoing discussion about the most appropriate cut-off point to use, we applied the Evenson cut-off points as recently suggested by Trost et $a l^{(18,19)}$ and reported $\mathrm{cpm} / \mathrm{d}$, which enables comparison between studies. Another limitation is the fact that hip-mounted accelerometers are not able to discriminate between sitting and standing while a tight-mounted accelerometer such as the ActivPAL ${ }^{\mathrm{TM}}$ is able to provide posturerelated information ${ }^{(29)}$. Although there is some evidence that an accelerometer cut-off point of $100 \mathrm{cpm}$ provides a good estimate of 8-12-year-old children's sitting time during school hours ${ }^{(30)}$, it may be possible that sedentary time measured in the present study does not only reflect the time children were being seated during the day. We also acknowledge that only a sub-sample of children wore an accelerometer, of which a relatively large number provided insufficient data, and that satisfying the inclusion criteria for our study was associated with sociodemographic characteristics of the children. Finally, not all questions used in the study were previously tested for their validity and reliability. However, it was the aim of the present study to add to the understanding of commonly used measures of which the validity is still unknown.

\section{Acknowledgements}

Financial support: This work was done as part of the IDEFICS study (www.idefics.eu). The authors gratefully acknowledge the financial support of the European Community within the Sixth RTD Framework Programme Contract No. 016181 (FOOD). Additionally, A.M.S.-P. received financial support by Fundación Cuenca Villoro (Spain). Both funders had no role in the design, analysis or writing of this article. The information in this document reflects the authors' view and is provided as is. Conflict of interest: None. Authorship: The work presented here was carried out in collaboration between all authors. V.V. and I.D.B. defined the research questions, carried out the analyses, interpreted the results and drafted the manuscript. S.D.H., K.B., G.B., C.H., G.E., K.K., E.K., Y.P., L.R., A.M.S.-P. and L.M. discussed the analyses, the interpretation and the presentation of the data in the manuscript. All authors have contributed to, seen and approved the manuscript. Ethics of buman subject participation: Ethical approval for the study was granted by the respective ethical committees in all participating centres.

\section{References}

1. Sirard JR \& Pate RR (2001) Physical activity assessment in children and adolescents. Sports Med 31, 439-454.

2. Lubans DR, Hesketh K, Cliff DP et al. (2011) A systematic review of the validity and reliability of sedentary behaviour measures used with children and adolescents. Obes Rev $\mathbf{1 2}$, 781-799.

3. Cleland V, Timperio A, Salmon J et al. (2010) Predictors of time spent outdoors among children: 5-year longitudinal findings. J Epidemiol Community Health 64, 400-406.

4. Burdette HL \& Whitaker RC (2005) A national study of neighborhood safety, outdoor play, television viewing, and obesity in preschool children. Pediatrics 116, 657-662.

5. DeMattia L, Lemont L \& Meurer L (2007) Do interventions to limit sedentary behaviours change behaviour and reduce childhood obesity? A critical review of the literature. Obes Rev 8, 69-81.

6. Leung MM, Agaronov A, Grytsenko K et al. (2012) Intervening to reduce sedentary behaviors and childhood obesity among school-age youth: a systematic review of randomized trials. J Obes 2012, 685430.

7. Ahrens W, Bammann K, Siani A et al. (2011) The IDEFICS cohort: design, characteristics and participation in the baseline survey. Int J Obes (Lond) 35, Suppl. 1, S3-S15.

8. Suling M, Hebestreit A, Peplies J et al. (2011) Design and results of the pretest of the IDEFICS study. Int J Obes (Lond) 35, Suppl. 1, S30-S44.

9. Cliff DP, Reilly JJ \& Okely AD (2009) Methodological considerations in using accelerometers to assess habitual physical activity in children aged 0-5 years. J Sci Med Sport 12, $557-567$.

10. Ferreira I, van der Horst K, Wendel-Vos W et al. (2007) Environmental correlates of physical activity in youth - a review and update. Obes Rev $\mathbf{8}, 129-154$.

11. Burdette HL, Whitaker RC \& Daniels SR (2004) Parental report of outdoor playtime as a measure of physical activity in preschool-aged children. Arch Pediatr Adolesc Med 158, 353-357. 
12. School of Public Health, University at Albany, State University of New York (2013) Upstate KIDS. http://www. albany.edu/sph/upstatekids.php (accessed August 2013).

13. Rideout V, Roberts DF \& Foehr UG (2005) Generation M: Media in the Lives of 8-18 year olds. A Kaiser Family Foundation Study. Menlo Park, CA: The Henry J. Kaiser Family Foundation.

14. Penpraze V, Reilly JJ, MacLean CM et al. (2006) Monitoring of physical activity in young children: how much is enough? Pediatr Exerc Sci 18, 483-491.

15. Williams HG, Pfeiffer KA, O'Neill JR et al. (2008) Motor skill performance and physical activity in preschool children. Obesity (Silver Spring) 16, 1421-1426.

16. Loprinzi PD \& Trost SG (2010) Parental influences on physical activity behavior in preschool children. Prev Med 50, 129-133.

17. Evenson KR, Catellier DJ, Gill K et al. (2008) Calibration of two objective measures of physical activity for children. J Sports Sci 26, 1557-1565.

18. Trost SG, Loprinzi PD, Moore R et al. (2011) Comparison of accelerometer cut-points for predicting activity intensity in youth. Med Sci Sports Exerc 43, 1360-1368.

19. Trost SG, Fees BS, Haar SJ et al. (2011) Identification and validity of accelerometer cut-points for toddlers. Obesity (Silver Spring) 20, 2317-2379.

20. Nilsson A, Bo Andersen L, Ommundsen Y et al. (2009) Correlates of objectively assessed physical activity and sedentary time in children: a cross-sectional study (The European Youth Heart Study). BMC Public Health 9, 322.

21. Matthews CE, Chen KY, Freedson PS et al. (2008) Amount of time spent in sedentary behaviors in the United States, 2003-2004. Am J Epidemiol 167, 875-881.

22. Martin A, McNeill M, Penpraze V et al. (2011) Objective measurement of habitual sedentary behavior in pre-school children: comparison of ActivPAL with ActiGraph monitors. Pediatr Exerc Sci 23, 468-476.
23. Regber S, Novak M, Eiben G et al. (2013) Assessment of selection bias in a health survey of children and families - the IDEFICS Sweden-study. BMC Public Health 13, 418.

24. Hense S, Pohlabeln H, Michels N et al. (2013) Determinants of attrition to follow-up in a multicentre cohort study in children - results from the IDEFICS study. Epidemiol Res Int 2013, 936365.

25. Verloigne M, Van Lippevelde W, Maes L et al. (2013) Self-reported TV and computer time do not represent accelerometer-derived total sedentary time in 10 to 12 -yearolds. Eur J Public Health 23, 30-32.

26. Rey-López JP, Ruiz JR, Ortega FB et al. (2012) Reliability and validity of a screen time-based sedentary behaviour questionnaire for adolescents: The HELENA study. Eur $J$ Public Health 22, 373-377.

27. Biddle SJH, Gorely T \& Marshall SJ (2009) Is television viewing a suitable marker of sedentary behavior in young people? Ann Behav Med 38, 147-153.

28. Clark BK, Healy GN, Winkler EA et al. (2011) Relationship of television time with accelerometer-derived sedentary time: NHANES. Med Sci Sports Exerc $\mathbf{4 3}$, 822-828.

29. Davies G, Reilly JJ, McGowan AJ et al. (2012) Validity, practical utility, and reliability of the ActivPAL in preschool children. Med Sci Sports Exerc 44, 761-768.

30. Ridgers N, Salmon J, Ridley K et al. (2012) Agreement between ActivPAL and ActiGraph for assessing children's sedentary time. Int J Behav Nutr Phys Act 9, 15.

31. Cole TJ, Bellizzi MC, Flegal KM et al. (2000) Establishing a standard definition for child overweight and obesity worldwide: international survey. BMJ 320, 1240-1243.

32. Cole TJ, Flegal KM, Nicholls D et al. (2007) Body mass index cut offs to define thinness in children and adolescents: international survey. BMJ 335, 194. 